\title{
Free Immunoglobulin Light Chain Measurement
}

National Cancer Institute

\section{Source}

National Cancer Institute. Free Immunoglobulin Light Chain Measurement. NCI

Thesaurus. Code C156517.

The determination of the amount of free immunoglobulin light chains present in a sample. 